\title{
The mechanics and muscular control of constriction in gopher snakes (Pituophis melanoleucus) and a king snake (Lampropeltis getula)
}

\author{
Brad R. Moon* \\ Department of Biology, University of Michigan, Ann Arbor, MI 48109, U.S.A. \\ (Accepted 6 October 1999)
}

\begin{abstract}
Constriction of prey by gopher snakes Pituophis melanoleucus and king snakes Lampropeltis getula is highly variable in posture, muscular activity and force exertion. These snakes typically use lateral bends of the anterior trunk to wind the body into a vertical coil around the prey. Three common constriction postures are fully encircling loops that form a coil, partially encircling loops, and non-encircling loops that pinion the prey. Initial tightening of a coil occurs by winding or pressing the loops tighter to reduce the diameter of the coil. The epaxial muscles are highly active during striking and coil formation and intermittently active during sustained constriction. These results refute the hypothesis of a mechanical constraint on constriction in snakes with elongate epaxial muscles. Constricting gopher and king snakes can detect muscular, ventilatory and circulatory movements in rodent prey. In response to simulated heartbeats or ventilation in mice, the snakes twitch visibly, recruit epaxial muscle activity, and increase constriction pressure temporarily, but then quickly relax. Muscular activity and constriction pressure are increased most and sustained longest in response to muscular struggling in prey. Although muscle activity and pressure exertion are intermittent, the constriction posture is maintained until the prey has been completely still for several seconds; thus, a snake can reapply pressure in response to any circulatory, ventilatory or muscular movement by the prey. The pressures of $6.1-30.9 \mathrm{kPa}(46-232 \mathrm{~mm} \mathrm{Hg})$ exerted on small mammal prey by constricting snakes range from about half to over twice a mouse's systolic blood pressure, and are probably 10 times larger than the venous pressure. These high pressures probably kill mammalian prey by inducing immediate circulatory and cardiac arrest, rather than by suffocation alone.
\end{abstract}

Key words: snakes, feeding, constriction, muscle, electromyography, kinematics, gopher snake, Pituophis melanoleucus, king snake, Lampropeltis getula, biomechanics

\section{INTRODUCTION}

Constriction of prey appears to have been a key innovation in the evolution and radiation of snakes (Greene \& Burghardt, 1978; Cundall \& Greene, 1982; Greene, 1983, 1994). It is integral to the feeding biology of many snakes and is used to restrain prey from escape or selfdefence and to kill it before ingestion. Constriction involves looping of the trunk around a prey animal and squeezing it to death before ingestion.

As in other kinds of axial bending, constriction movements are produced by the axial musculature. The large cross-sectional areas of the complex epaxial muscles may support the exertion of large forces during axial

*All correspondence to: Department of Radiology, Box 357115, University of Washington Medical Center, Seattle, WA 98195-7115, U.S.A. E-mail: bmoon@u.washington.edu bending (Gasc, 1981). These muscles are hypothesized to bend large arcs of the trunk (Mosauer, 1932a,b; Gans, 1962; Ruben, 1977). A corollary of this hypothesis is that the long epaxial muscles do not contribute to the small-radius bending during constriction (Ruben, 1977). However, the vigorous striking and coiling movements in constriction have precluded study of its muscular basis because recording electrodes have been pulled out during previous pilot studies (Cundall, 1987). Despite this difficulty, understanding the muscular control of constriction is essential to understanding the diverse roles of the complex axial musculature of snakes.

Although constriction of mammalian prey is usually brief, it can be sustained for several minutes or longer for prey that struggle vigorously. Preliminary observations of postural and subcutaneous muscular movements in gopher snakes indicated that the snakes maintain 
Table 1. Numbers of snakes and feeding events used in quantitative analyses of electromyographic activity (EMG), pressure, and handling times. $\mathrm{L}=$ Lampropeltis getula $; \mathrm{P}=$ Pituophis melanoleucus.

\begin{tabular}{|c|c|c|c|c|c|}
\hline Snake & $\begin{array}{l}\text { Total no. } \\
\text { of feedings }\end{array}$ & EMG & Pressure & Handling time & Complete data ${ }^{b}$ \\
\hline L1 & $6(4 \mathrm{~d}, 21)$ & 6 & 6 & 6 & $6(4 \mathrm{~d}, 21)$ \\
\hline P5 & $1(11)$ & & & 1 & \\
\hline P8 & $1(1 \mathrm{~d})$ & & 1 & & \\
\hline $\mathrm{P} 10$ & $1(1 \mathrm{~d})$ & & 1 & & \\
\hline $\mathrm{P} 12$ & $5(2 \mathrm{~d}, 31)$ & 3 & 5 & 3 & $3(31)$ \\
\hline $\mathrm{P} 13$ & $4(2 \mathrm{~d}, 2 \mathrm{l})$ & 3 & 3 & 3 & $3(1 \mathrm{~d}, 21)$ \\
\hline $\mathrm{P} 17$ & $2(21)$ & 2 & 2 & 2 & $2(21)$ \\
\hline P19 & $3(31)$ & 3 & 2 & 3 & $2(21)$ \\
\hline $8^{c}$ & $23(10 \mathrm{~d}, 13 \mathrm{l})$ & 17 & 20 & 18 & $16(5 \mathrm{~d}, 11 \mathrm{l})$ \\
\hline
\end{tabular}

\footnotetext{
${ }^{a}$ Numbers in parentheses indicate numbers of dead (d) and live (l) prey.

${ }^{\mathrm{b}}$ Number of feeding events for which combined EMG, pressure, and handling time data were available for each snake.

${ }^{\mathrm{c}}$ Total numbers of snakes and constriction events represented in each data set.
}

constriction posture, but recruit axial muscles and exert forces only intermittently in response to struggling movements by the prey. Sustained constriction posture with intermittent muscular activity and force exertion has not been reported in the literature, and therefore requires confirmation by recording the muscular activity and forces exerted by snakes during constriction.

Constriction is usually assumed to kill prey by suffocation because the forces exerted appear to interfere with breathing in the prey. However, constriction kills small mammals faster than would be expected if suffocation were the proximate cause of death (McLees, 1928; Hardy, 1994). Consequently, McLees (1928) and Hardy (1994) hypothesized that constriction arrests the circulation of rodent prey and thus leads to death faster than would suffocation alone.

As part of a larger project on the roles of the epaxial muscles in vertebral bending in snakes (Moon, 1998), I examined the mechanics and muscular control of constriction. Specifically, the kinematics, epaxial muscle activity, and forces of constriction were recorded in several gopher snakes Pituophis melanoleucus affinis and one king snake Lampropeltis getula nigrita. Because striking and coil formation have been studied previously in gopher snakes (Greenwald, 1974, 1978; de Queiroz, 1984), I emphasized the mechanics and control of sustained constriction, subsequent to the strike and initial formation of a coil. Toward this end, the following hypotheses were tested:

(1) The epaxial muscles produce, or at least contribute to, the small-radius bends used for constriction. In addition, the electromyographic recordings allow a preliminary test of whether the epaxial muscles exhibit different frequencies of firing during sustained constriction than they do during striking and coil formation or other kinds of axial bending.

(2) Force is exerted intermittently during sustained constriction postures. Some prey movements were manipulated during constriction in an attempt to elicit maximal and prolonged constriction effort; hence, the data allow comparisons of the effects of different kinds of prey movements on constriction force and duration.

(3) Constriction is sufficiently forceful to kill prey by circulatory arrest.

\section{MATERIAL AND METHODS}

\section{Specimens and anatomy}

For this study, I used 7 gopher snakes (5 Pituophis melanoleucus affinis and $2 P$. m. deserticola, the latter for pressure recordings only) and 1 king snake (Lampropeltis getula nigrita; Tables $1 \& 2$ ). The king snake was used in preliminary experiments in which I tested the recording techniques; although the single specimen is an insufficient sample on which to base generalizations, the limited results from this snake illustrate several kinematic and electromyographic similarities to the gopher snakes. Table 1 lists the numbers of constriction events analysed for each snake and type of data. All snakes were housed on a seasonal light cycle and were fed laboratory mice weekly to monthly as needed; snakes were not fed for at least 1 week before use in the experiments. The experimental data were augmented with visual observations of constriction in several additional boid snakes (3 Boa constrictor, 1 Charina bottae, 1 Epicrates cenchria, 2 Eryx colubrinus, 5 Python regius and $1 P$. reticulatus) and colubrid snakes (1 Elaphe obsoleta obsoleta, 2 Lampropeltis getula holbrooki, 1 Lampropeltis zonata, 13 Pituophis melanoleucus affinis and P. m. deserticola and 1 Trimorphodon biscutatus).

To examine the anatomical basis of constriction, 3 preserved gopher snakes were dissected in detail before the experiments, and 2 more specimens were dissected after use in the experiments. Additional anatomical data were obtained from literature accounts (Mosauer, 1935; Pregill, 1977; Gasc, 1981; Jayne, 1982). The dissections guided the placement of the EMG electrodes and 
Table 2. Sizes and electrode placements for the individuals of Lampropeltis getula (L) and Pituophis melanoleucus (P) from which muscle activity was recorded. SVL, snout-vent length; TL, tail length; BV, number of body (trunk) vertebrae from snout to vent; TV, number of tail vertebrae; SSP, M. semispinalis; LD, M. longissimus dorsi; IL, M. iliocostalis; V, vertebra

\begin{tabular}{|c|c|c|c|c|c|}
\hline Snake & Mass (g) & $\mathrm{SVL}+\mathrm{TL}(\mathrm{mm})$ & $\mathrm{BV}+\mathrm{TV}$ & Muscles & Electrode placement \\
\hline L1 & 378 & $1110+150$ & $226+49$ & SSP, LD & Bilateral V50, V75 \\
\hline P12 & 614 & $1255+190$ & $233+57$ & SSP, LD, IL & Bilateral V50, V75 \\
\hline P13 & 596 & $1310+170$ & $241+61$ & $\mathrm{SSP}, \mathrm{LD}, \mathrm{IL}$ & Bilateral V25, V75 \\
\hline P17 & 561 & $1105+130$ & $243+52$ & $\mathrm{SSP}, \mathrm{LD}, \mathrm{IL}$ & Bilateral V25, V75 \\
\hline P19 & 759 & $1180+100$ & $244+33$ & SSP, LD, IL & Bilateral V25, V75 \\
\hline
\end{tabular}

revealed the highly complex anatomy of the epaxial musculature.

In gopher snakes, the architecture of the epaxial muscles and tendons is fairly uniform from $c$. vertebra 23 along the trunk to the posterior trunk. Therefore, in the anatomical descriptions below, the epaxial muscle anatomy in the sonoran gopher snake $P$. m. affinis in the mid-trunk is briefly described. The anatomical terminology corresponds to that of Gasc (1981), and the general term 'insertion' is used to avoid ambiguities with multiple origins and insertions; similarly, the terms 'anterior' or 'posterior' are used for tendons to avoid confusion over tendons of origin and insertion in the complex muscle-tendon chain. The number of vertebrae spanned by muscular-tendinous segments represents the number of joints spanned by the muscle and tendon tissue (i.e. it includes 1 vertebra of insertion); note that this method of counting vertebrae differs from that of Jayne (1982) by not including both vertebrae of insertion.

\section{General experimental design}

For all experiments, the snakes were placed in a $300 \times 500 \mathrm{~mm}$ glass aquarium with an open top. Electrode leads and pressure tubing exited through the top of the cage and allowed free movement of the snakes and attached wires and tubing. The ambient temperatures under the video spotlights ranged from 23 to $28^{\circ} \mathrm{C}$, which encompassed the optimal temperatures for feeding movements in gopher snakes (Greenwald, 1974); the slow change in temperature did not seem to affect the feeding movements of the snakes.

In different experiments, dead and live* mice were offered as prey (7.5-36 g, 1.3-6.8\% of snake body mass); in 2 experiments rats $(53.5$ and $122.5 \mathrm{~g}, 7 \%$ and $20 \%$ of snake body mass) were fed to the snakes to test larger prey sizes. In the first set of experiments pre-killed mice, maintained at body temperatures of $38-40^{\circ} \mathrm{C}$, were used to control the cues produced by the constricted prey. Each dead mouse was instrumented with 2 small pressure-sensing bulbs connected to physiological pressure transducers. One bulb was connected to an external hand pump, which I used to produce pulses that

\footnotetext{
* Editor's footnote: The feeding of live vertebrates to captive predators is not permitted under national legislation in the U.K.
}

simulated heartbeat and respiratory movements of the prey. A second bulb (described later) was implanted for recording the pressures exerted by the snakes in response to the movements of the prey.

To simulate mouse heartbeats, I pulsed the implanted stimulus bulb quickly at low amplitudes (2-4 pulses/s, c. 1-2 mm expansion); to simulate lung ventilations, I pulsed the stimulus bulb slowly at large amplitudes (0.5-1 pulses/s, 3-5 $\mathrm{mm}$ expansion). To simulate movements of the entire body of they prey, I twitched a string that was tied to the hind legs. The simulated heartbeats and ventilatory movements did not seem to elicit prolonged or maximal constriction effort, so these manipulations were not continued in later experiments.

In a second set of experiments, snakes were fed live mice to elicit constricting responses to natural movements by the prey. To record the constriction pressures in these experiments, each mouse was implanted with 1 small pressure-sensing bulb in the body cavity; the bulb was connected to a physiological pressure transducer (described later) for recording coelomic pressures during constriction. In these experiments, a string tied to a hind leg of the mouse was gently pulled to elicit longer and more forceful constriction.

In all experiments, the mice were offered to the snakes with long forceps. Once the snakes struck the prey, the simulated movements were started during coiling and repeated periodically during sustained constriction. In describing constriction postures below, the following terminology is used:

loop: a bend of the body pressed against the prey (Greene \& Burghardt, 1978)

pinion: 1 or more loops that push the prey against a surface but do not bend around it (de Queiroz, 1984)

non-overlapping loop: a loop that partially encircles the prey (Mori, 1991)

coil: 1 or more loops that fully encircle the prey (Greene \& Burghardt, 1978). In forming a coil, loops may be wound regularly in 1 direction, which usually involves the prey being turned as the loops are applied, or wrapped from 2 or more directions around the prey, with little or no turning of the prey (Greene \& Burghardt, 1978). The resulting coil may be vertical or horizontal relative to the substratum (Greene \& Burghardt, 1978), and may result in the lateral or the ventral surface of the snake pressing against the prey. 


\section{Videography}

The experiments were taped with a Sony S-VHS video camera placed horizontally $c .2 .5 \mathrm{~m}$ from the cage. The cage was lined on the bottom and back with a grid for scale and contained a mirror at $45^{\circ}$ from the bottom to reflect a dorsal view into video camera. The video speed of $30 \mathrm{frames} / \mathrm{s}$ proved adequate for the slow movements of sustained constriction, although a higher recording speed would be necessary for detailed analyses of the striking movements.

For video data acquisition, Measurement TV (MTV) and FIN (both by DataCrunch Software) were used to digitize selected images for measurement of constriction curvature (1/radius of curvature in $\mathrm{cm})$ and vertebral lateral bending angles. MTV uses the horizontal and vertical scales in the video field to correct for camera angle and adjust the image shape. The vertebral midline and a cross-bar at every tenth vertebra were painted on the snakes to facilitate digitizing. To calculate vertebral bending angles, FIN uses a finite-element analysis based on the digitized vertebral midline of an animal. For calculation of the bending angles, the length of each finite element was set to correspond to 1 vertebra in the snake, measured as the distance between adjacent ventral scales (Alexander \& Gans, 1966). Vertebral curvature was calculated for 9 video frames from 5 snakes, and vertebral bending angles were calculated for 1 video frame each for 6 snakes.

\section{Electromyography}

To record the activity of the epaxial muscles, bipolar hook electrodes were implanted (Loeb \& Gans, 1986) into the semispinalis portion (SSP) of the M. spinalissemispinalis, the M. longissimus dorsi (LD), and the M. iliocostalis (IL) in the snakes (Table 2). Electrodes were implanted bilaterally at 2 longitudinal positions between vertebrae 25 and 75 , as indicated by ventral scale counts (Alexander \& Gans, 1966), to detect any bilateral differences in muscle activity and any longitudinal propagation of muscle activity. The interelectrode distance of 25-50 vertebrae also helped to ensure recording from regions of the trunk that looped around the prey.

Electrodes were constructed from Teflon coated stainless steel wire (Medwire, Sigmund Cohn Corp.). The electrode bipole spacing was $1.0 \mathrm{~mm}$ and the bare recording surface of each bipole measured $0.5 \mathrm{~mm}$. Hook electrodes were used in these experiments because they are less invasive than patch electrodes, which in pilot studies seemed to interfere with normal feeding behaviour.

Surgical implantation and removal of the hook electrodes ensured proper placement in the target muscle. For electrode implantation, the snakes were first anaesthetized with Halothane using an open drop method (Bennett, 1996). Then a short longitudinal incision was made in the skin and underlying fascia, a dissecting probe was used to identify the position of the target muscle, and the electrodes were inserted via hypodermic needle into the muscle. A small amount of cyanoacrylate glue and a surgical spray wound-dressing was used to hold the electrodes in place and to seal the leads at the incision in the skin. Small patches of tape were used to hold the electrode leads against the dorsal skin at intervals along the length of the instrumented trunk, so that the leads formed 1 bundle that connected to the amplifier cabling beyond the posterior electrode insertion site. The ends of the lead wires were soldered to Amphenol gold mini-connector pins, which were connected to preamplifier cables hung from above the experimental cage. The suspended cabling allowed free movement of the snake with minimal resistance from the cabling.

The electrodes remained in place for up to 1 week; electrode impedance was stable over this period, and the electrodes were well tolerated by the snakes. Upon surgical removal of the electrodes, I used a probe to isolate the instrumented muscle and confirm the electrode placement.

The EMG signals were amplified by Tektronix FM 122 or Tektronix 26A2 differential preamplifiers (gain $=1000$ or 5000 ; bandwidth $100-10000 \mathrm{~Hz}$ ), then by Honeywell 117 DC amplifiers (gain $=1$ or 5) to stabilize the signal current, and then were recorded on FM tape. To test for the presence of low frequency signals, which may indicate the activity of tonic fibres (Carrier, 1989), the lower band limit of the preamplifiers was set to $10 \mathrm{~Hz}$ for several short periods during different phases of constriction, and digital filtering was not used. The signals were recorded at $19.05 \mathrm{~cm} / \mathrm{s}$ on a Honeywell 101 medium-band tape recorder (bandwidth $=100-2500 \mathrm{~Hz}$ ).

The EMG data were digitized and analysed using a DOS-based software package (DataCrunch Software) that contained an A-D signal acquisition program, a digital finite impulse response filter, and an analysis program. The signals were digitized at $8000-10000 \mathrm{~Hz}$ (real time) per channel using a Keithley 12-bit analog to digital converter, and then digitally filtered below 100 $\mathrm{Hz}$ and above $2500 \mathrm{~Hz}$. These sampling rates were sufficient to reproduce accurate EMG spike frequencies and amplitudes (Jayne et al., 1990; Moon, 1996).

\section{Plethysmography}

The forces exerted by the snakes on the prey produce elevated pressures in the bodies of the prey, which can be recorded using plethysmography. For recording these pressures, mice were instrumented with small water-filled rubber bulbs implanted into the body cavity. The bulbs were connected to physiological pressure transducers via water-filled polyethylene tubing. Constriction pressures were recorded from 7 snakes and 20 feedings (Table 1 ).

For the initial experiments, Gould-Statham P23 physiological pressure transducers connected to Honeywell 


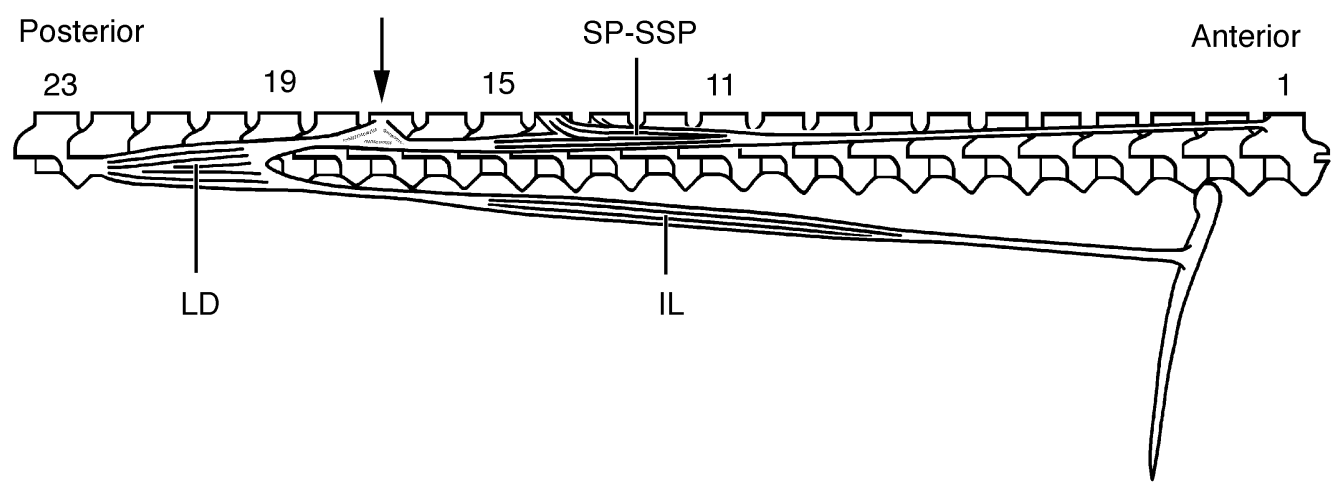

Fig. 1. Epaxial muscular anatomy of the mid-trunk of the gopher snake Pituophis melanoleucus. IL, M. iliocostalis; LD, M. longissimus dorsi; SP-SSP, M. spinalis-semispinalis. Numbers, vertebral position from the anterior insertion of the muscletendon chain; arrow, the diffuse portion of the SSP-LD tendon in the surrounding connective tissue, which is not an insertion on the vertebra.

Accudata 113 Bridge Amplifiers were used. The transducer outputs were calibrated over $0-40 \mathrm{kPa}(0-300 \mathrm{~mm}$ $\mathrm{Hg}$ ) above atmospheric pressure, which encompassed the pressures recorded during the constriction events. For later experiments, I used a Harvard Apparatus blood pressure transducer, calibrated over the same range of pressures as the P23 transducers. I tested both transducers for stability of output over extended periods, ranging from 1 to $30 \mathrm{~min}$, and found no measurable drift. The pressure signals were then recorded and analysed together with the EMG signals. The video recordings were synchronized with the pressure and EMG recordings via an analog time signal that was recorded on both EMG and video tapes.

\section{Analyses}

Combined kinematic, electromyographic, and force data were analysed for 16 constriction events from 4 gopher snakes and 1 king snake (Table 1). Partial quantitative data were analysed for 4 additional constriction events (Table 1). In addition, qualitative patterns of constriction by several snakes of the other species listed above were observed.

From the video data, the duration of several phases of prey handling, including (1) time from strike contact to the initiation of coiling, (2) time required to form a stable coil or loop posture, and (3) duration of coiling from the beginning of the stable posture to the visible loosening of the loops or coil were calculated. I first tested for differences in prey handling times between the single king snake and the gopher snakes, and found no significant differences (see Results); consequently, the king snake and gopher snake data were pooled in the final ANOVAs. The effects of prey condition (live $v s$ dead) on these components of handling time were tested using 2-way ANOVAs with each handling time variable as a dependent variable and with individual snake and prey condition as independent variables. Although this test may confound differences in prey mass and differences among individuals in the experimental manipulation of prey movements, the results were used to examine broad trends, rather than specific ranges, of prey handling time.

From the digitized EMG and pressure data, the frequency content of epaxial muscle activity and the peak pressure exerted during constriction were measured. The frequency content of the muscle activity was analysed using Fourier transforms to search for potential differences in active fibre types. The intermittent pattern of muscle activity and pressure precluded comparison of the total duration of muscle activity and pressure to the duration of coil posture. Therefore, to test the hypothesis that force exertion is intermittent during sustained constriction posture, I searched for periods of low or zero pressure during sustained posture and muscle activity.

\section{RESULTS}

\section{Muscular anatomy}

Each of the epaxial muscles, Mm. spinalis-semispinalis (SP-SSP), longissimus dorsi (LD), and iliocostalis (IL) consists of overlapping segments that together form a longitudinal column. These three groups of muscles are interconnected and form a chain of muscle-tendon segments (Fig. 1). The anterior tendon of the SP-SSP inserts on the dorsal posterior edge of a neural spine and extends posteroventrally for 10 vertebrae to the SPSSP fibres. The SP-SSP fibres share the anterior tendon, but split posteriorly into discrete SP and SSP muscles. From the anterior SP-SSP tendon, the SP fibres run posterodorsally, spanning three vertebrae, to insert on the tendons of two adjacent segments of the M. multifidis (which was not studied here). The SSP fibres span four vertebrae posteroventrally and insert on the anterior dorsal tendon of the LD. The SSP-LD tendon begins as a discrete ribbon but then becomes obscured in the fascia overlying the SSP column; within one 
segment, the tendon then coalesces posteriorly into the discrete anterior dorsal tendon of the LD (Fig. 1, arrow). This unusual tendon anatomy is difficult to dissect, and may vary to some degree among individuals. Overall, this tendon spans four vertebrae between the SSP and LD fibres. The fibres of the LD extend posteriorly four vertebrae and terminate on a vertebral prezygapophysis. Overall, the SSP-LD system spans 22 vertebral joints.

The LD also gives rise to an anterior ventral tendon that spans four vertebrae anteriorly and connects to the fibres of the IL. The IL extends anteriorly seven vertebrae to insert on an anterior tendon, which spans five more vertebrae and inserts on a rib. The IL-LD system spans 20 vertebrae. Overall, the epaxial muscle-tendon system spans 22 vertebrae and has four insertions on the skeleton.

The deeper hypaxial muscles are generally segmental, with a few spanning two to three vertebrae or ribs (Mosauer, 1935; Gasc, 1974, 1981; Pregill, 1977; Jayne, 1982), and have small cross-sectional areas. Because of these features, they have not been hypothesized to be important axial flexors in snakes. In contrast, because the epaxial muscles are much larger and have more complex interconnections, they are hypothesized to be important lateral flexors of the vertebral column (Gasc, 1981).

The limited data available indicate that the musculature of king snakes is similar to that of gopher snakes (Mosauer, 1935, $n=$ unspecified for L. getula and P. melanoleucus; Pregill, 1977, $n=4$ L. getula, $n=1$ P. melanoleucus; Jayne, 1982, $n=1$ L. getula, $n=5$ $P$. melanoleucus). Therefore, the general conclusions about anatomy-function relationships made here for gopher snakes probably also apply to king snakes.

\section{Strike and coil formation}

\section{Kinematics}

The mice were offered to the snakes via forceps, which precluded the need for a long strike. Upon striking live rodents, the snakes usually applied loops with continuous forward movement following the strike, without retracting the prey. In contrast, upon striking dead mice, the snakes retracted the mice from the forceps but did not immediately apply constricting loops. In these cases, neither simulated ventilation nor simulated heartbeats induced constriction, although vigorous shaking of the prey with forceps or a string tied to the legs was usually sufficient to induce coiling. Besides the differences in prey retraction and immediate $v s$ delayed application of loops, the patterns of loop formation were similar for live and dead prey.

During the strike, the head and anterior neck were held elevated above the substratum, and the posterior trunk remained at rest on the substratum. Both gopher snakes and the king snake most often bent the head and neck laterally to wind one or more fully encircling loops
( $n=16)$ or wrap partially encircling loops $(n=1)$. The fully encircling loops were wound around the prey by rotating the prey about a vertical axis. The coil application pattern was obscured in six of the video records by overlapping loops of the body. In addition, three uninstrumented gopher snakes pinioned mice against the substratum or other objects. One of these involved partially encircling loops, one involved a single convex bend of the trunk pushing the prey against the wall of the cage, and one involved pinioning by the jaws alone.

Most snakes formed vertical loops; in two instances, the king snake and one gopher snake then shifted to a diagonal coil. In all but one of the coils, the dorsum of the snake faced its chin whereas in one coil the venter of the snake faced the dorsal surface of its head. These two coil postures are equivalent to a vertical coil with the head on the top (the former) or bottom (the latter) of the coil; neither posture involved a twist in the initial loop. In both gopher snakes and the king snake, coils occasionally involved slight axial twisting that produced vertical (ventral) bending in parts of the trunk. The other colubrid snakes observed usually used lateral bending to produce vertical coils, whereas the boid snakes used either lateral (Charina bottae, Epicrates cenchria, Eryx colubrinus) or ventral (Python regius, $P$. reticulatus) bending to produce horizontal coils; pinioning was not used by these other colubrid and boid snakes.

Initial tightening of a coil, by reduction of loop diameter, was continuous with coil formation. This pattern was somewhat visible in light video records, but is conspicuous in X-ray videos of constricting pine snakes $P$. melanoleucus lodingi (N. Kley, pers. comm.). Partially encircling and pinioning loops were tightened by pressing the loops together, or against an external object, more firmly.

Prey handling times did not differ significantly between species (independent $t$-tests: strike-coil formation delay, $t_{13}=-1.52, P=0.15$; coil formation time, $t_{16}=1.24, P=0.23$; coil duration $t_{15}=-1.89, P=0.08$; peak pressure, $t_{6}=-0.29, P=0.79$ ); note that in these preliminary $t$-tests, gopher snakes were pooled without regard to potential individual differences. Consequently, data from the gopher snakes and the single king snake were pooled for the ANOVAs of kinematic variables, which did take into account potential differences among individuals (Table 3 ).

The timing of loop and coil formation was highly variable (Table 3). The differences in handling times between live and dead prey were not significant in this small sample, but were in the expected directions (Table 3): coil formation time was shorter and coil duration was longer for live than for dead prey. The strike-coil delay was longer for live prey than for dead prey, which may reflect the difficulty of coiling around moving prey. The high variability in these handling times may account for the lack of significant differences between species, although larger samples are needed to resolve this possibility.

In a small sample of constriction events by five 
Table 3. Statistics and pooled ANOVA results for prey handling times during constriction by one king snake Lampropeltis getula and four gopher snakes Pituophis melanoleucus. Values given are mean \pm SD and range ( $n=$ number of constriction events); $F$ values are subscripted with the degrees of freedom.

\begin{tabular}{lllcc}
\hline Prey condition & Strike-coil delay $(\mathrm{s})$ & Coil formation time $(\mathrm{s})$ & Coil duration $(\mathrm{s})$ & Peak pressure $(\mathrm{kPa})$ \\
\hline Live & $2.54 \pm 3.96$ & $6.26 \pm 5.62$ & $204.75 \pm 105.75$ & $13.98 \pm 4.05$ \\
& $0-11.7(n=13)$ & $1.7-19.6(n=13)$ & $74431(n=12)$ & $9.47-19.06(n=8)$ \\
Dead & $0.16 \pm 0.23$ & $9.27 \pm 6.14$ & $160.55 \pm 99.86$ & $15.30 \pm 7.62$ \\
& $0-0.5(n=5)$ & $4.5-19.8(n=5)$ & $23-275(n=5)$ & $6.13-30.93(n=9)$ \\
& $F_{6}=1.79, P=0.19$ & $F_{6}=0.50, P=0.79$ & $F_{6}=3.98, P=0.03^{a}$ & $F_{6}=0.39, P=0.87$ \\
\hline
\end{tabular}

${ }^{a}$ Significance due only to effect of individual $\left(F_{5}=4.49, P=0.02\right)$.
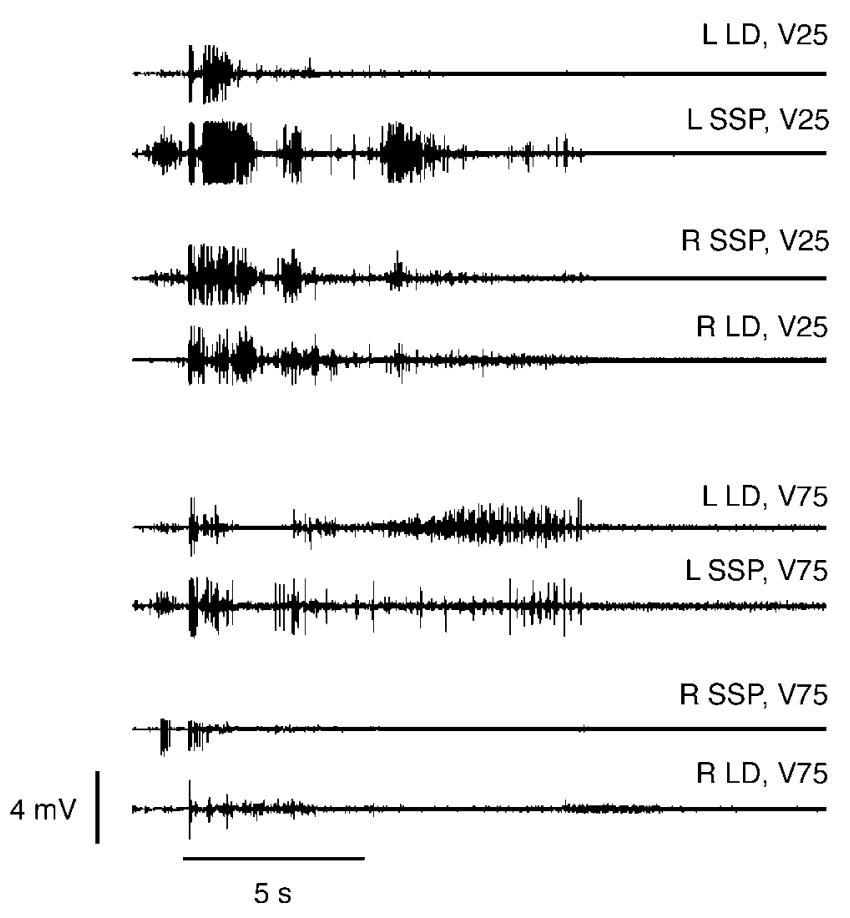

Fig. 2. Epaxial muscle activity during left lateral bending and constriction coil formation around a dead mouse by Pituophis melanoleucus no. 13. This sequence shows the first $20 \mathrm{~s}$ of a $234 \mathrm{~s}$ constriction event. The electrodes at vertebra 25 were anterior to the mouse, but the electrodes and muscles at vertebra 75 were in direct contact with the mouse. V, vertebra at which each EMG electrode was implanted in the muscle; SSP, semispinalis part of the M. spinalis-semispinalis. Other abbreviations as in Fig. 1.

snakes, fully encircling and tightened loops had vertebral curvatures of $0.35-1.33$ (mean $\pm \mathrm{SD}=0.58 \pm 0.30$, $n=9)$ over 10 vertebrae, which usually represented slightly more than half of a single constricting loop. In a sample of six snakes, mean vertebral bending angles over 10 vertebrae in a fully tightened loop ranged from 10.28 to $17.66^{\circ}$ per joint (overall range $=5.21-32.95$ ).

\section{Muscle activity}

During striking and coil formation, epaxial muscle activity was extremely variable. The low videotape speed precluded quantitative analysis of kinematics and associated muscle activity during the fast movements of striking. However, epaxial muscle activity and associated increases in pressure were clearly pronounced during the constriction. In all snakes, muscle activity during coil formation was often synchronous and largely bilateral over at least 25 vertebrae (Fig. 2), which may partly reflect elevation of the head and neck during striking and coil formation. Unilateral concave muscle activity often appeared to have larger magnitudes than convex activity during lateral bending, although this pattern was obscured by high variability. Although manipulation of prey movements probably affected both postural and muscular activity patterns, nonmanipulated postures and muscle activity patterns seemed equally variable.

\section{Sustained constriction}

\section{Kinematics}

Once constricting loops were firmly applied to the prey, the snake usually ceased major postural adjustments. Constriction posture, from the beginning of the stable coil posture to visible loosening, was held for $74-431 \mathrm{~s}$ around living mice and for 23-275 s around dead mice (Table 3). Constriction lasted significantly longer for living than for dead prey (Table 3). The duration of constriction increased with increasing prey mass (Fig. 3), although the manipulation of prey movements to elicit prolonged and forceful constriction precluded statistical analysis of this trend.

After initial coil formation, subsequent tightening of the coil appeared to be achieved by two methods: reduction of the coil diameter, particularly when loops were wound tighter in response to movements of the prey, and slight abduction of the body wall, perhaps via action of the M. levator costae or other body wall muscles.

\section{Muscle activity and force exertion}

During sustained constriction in both gopher snakes and the king snake, epaxial muscle activity and pressure exhibited three general patterns: 


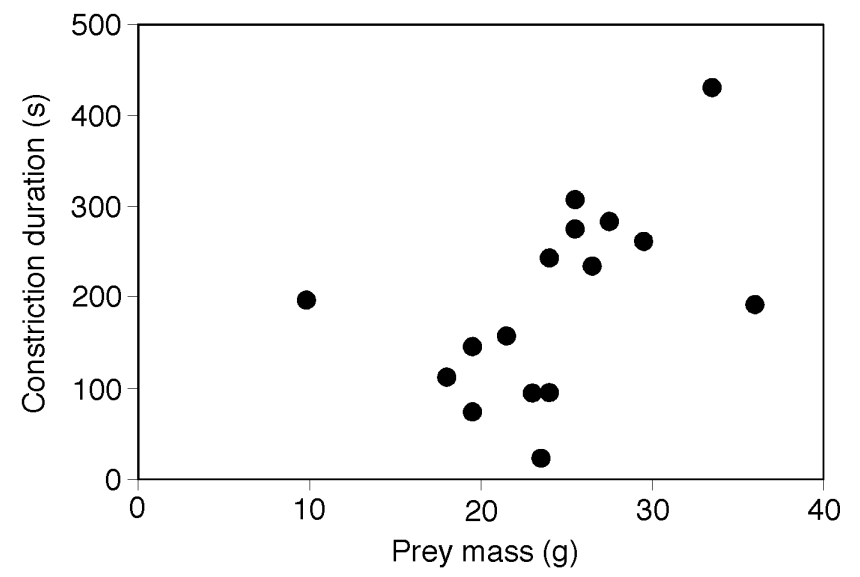

Fig. 3. The relationship between constriction duration and prey mass in a combined sample of Pituophis melanoleucus ( $n=11$ feeding events) and Lampropeltis getula $(n=5$ feeding events). Some of the variability may have resulted from the manipulation of prey movements.
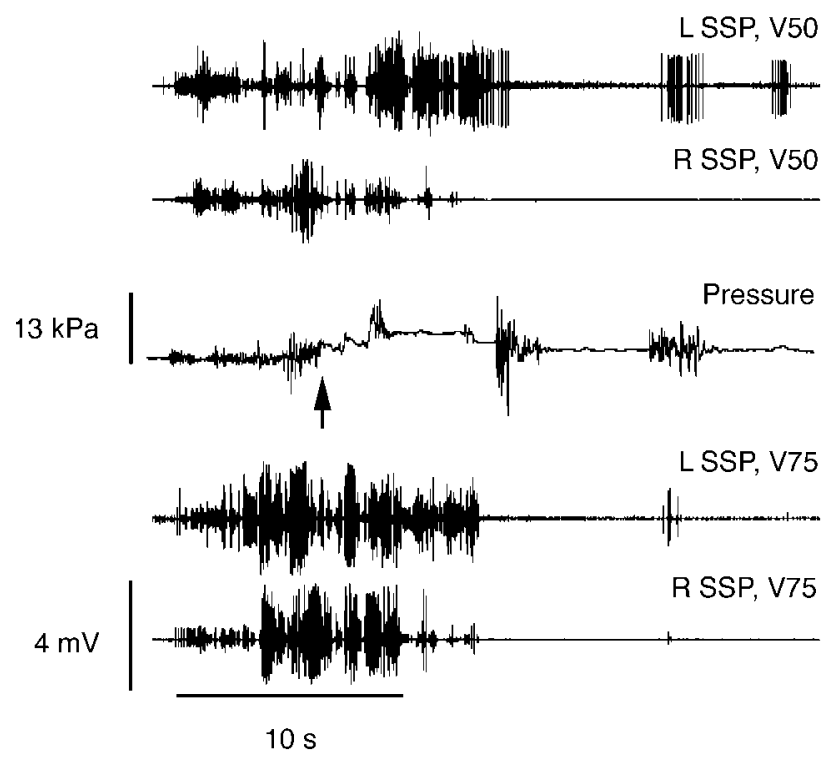

Fig. 4. Epaxial muscle activity and constriction pressure in a dead mouse during a right turn constriction coil by Lampropeltis getula. This sequence represents $30 \mathrm{~s}$ of a $158 \mathrm{~s}$ constriction event. Both electrode sites, at vertebrae 50 and 75 , were in direct contact with the mouse. In this example, the initial high pressure decreased rapidly but lower pressure was sustained well after the cessation of muscle activity. Arrow, beginning of stable coil posture. Abbreviations as in Figs $1 \& 2$.

(1) Muscle activity and pressure decreased quickly after coil formation or prey movements (Fig. 4). Initial high pressures declined rapidly, but lower pressures were often sustained well after the muscle activity ceased.

(2) Muscle activity ceased quickly after coil formation or prey movements, but moderate to high pressure was sustained after the muscles decreased or ceased activity (Fig. 5). Often the electrode-bearing

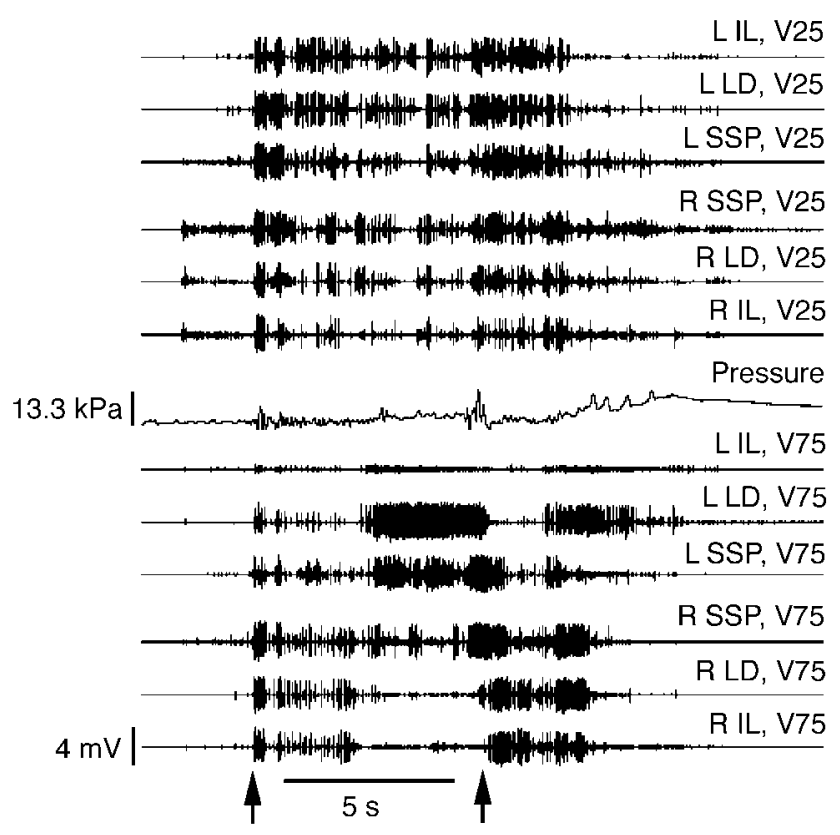

Fig. 5. Epaxial muscle activity and constriction pressure in a live mouse during a sustained left lateral coil by Pituophis melanoleucus no. 17. This sequence represents the first $20 \mathrm{~s}$ from a $74 \mathrm{~s}$ constriction event. Both electrode sites, at vertebrae 25 and 75, were in direct contact with the mouse. Arrows, beginning (left) and end (right) of artificial shaking of the mouse. In this example, pressure was sustained well after muscle activity decreased and ceased. Abbreviations as in Figs $1 \& 2$.

muscle segments were not in direct contact with the prey.

(3) In constriction events in which the electrode-bearing muscles were in direct contact with the prey, muscles were active and pressure tended to be sustained for long periods, both after coil formation and in response to movements of the prey (Fig. 6).

None of the constriction events involved continuous muscle activity or force exertion for the entire duration of the constriction posture.

During sustained constriction, as during coil formation, the epaxial muscles were often active bilaterally. Some of this bilateral activity may be associated with apparent stretching movements in which the loops seem to pull slightly apart from one another. During static constriction posture, epaxial muscles often shifted to largely unilateral activity, particularly in loops around the midbody of the prey. Although the epaxial muscles on one side of the body were occasionally activated independently of one another, there were no clear differences in activity among muscles. Fourier analyses indicated that throughout constriction, epaxial muscles fired with the same range of frequencies as in lateral undulatory locomotion. Setting the lower band limit of the amplifiers to $10 \mathrm{~Hz}$ during constriction, both with and without obvious muscle activity, did not reveal low frequency signals that may indicate tonic fibre activity. 


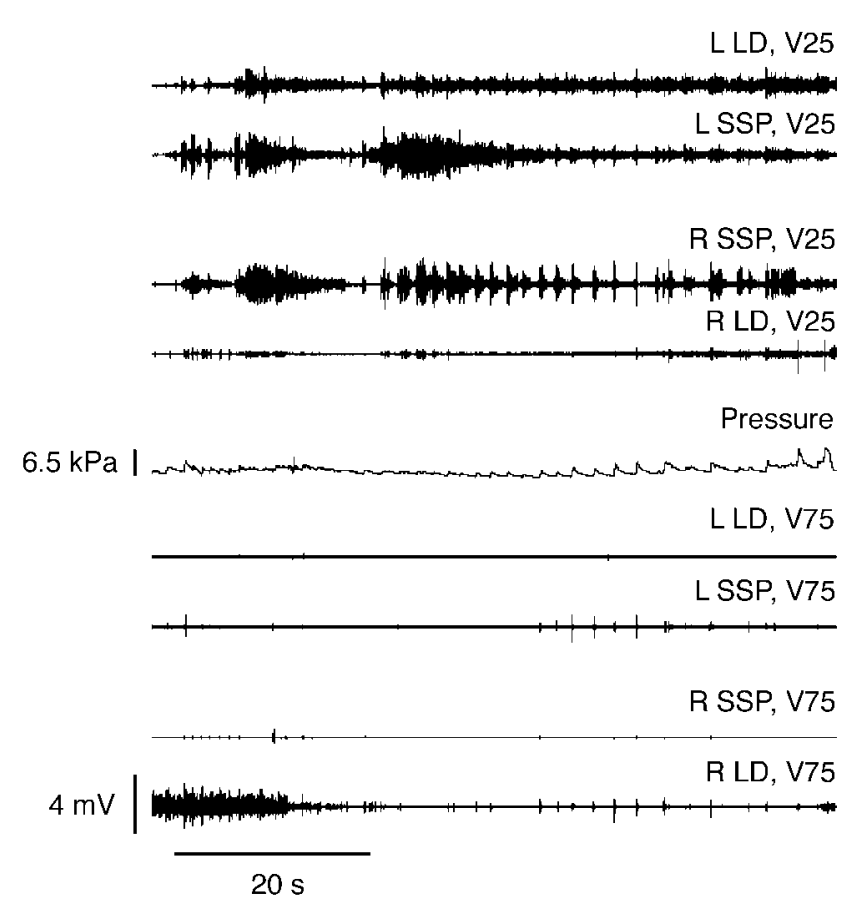

Fig. 6. Epaxial muscle activity and constriction pressure in a live mouse during a sustained right lateral coil by Pituophis melanoleucus no. 13. This sequence represents $70 \mathrm{~s}$ from the middle of a 192 s constriction event. Both electrode sites, at vertebrae 25 and 75, were in direct contact with the mouse. In this example, muscle activity and pressure were sustained together. The repeated pressure peaks indicate snake responses to natural twitches by the mouse. Abbreviations as in Figs 1 \& 2.

\section{Responses to prey movements}

All the snakes tested were able to detect all the simulated struggling cues in the instrumented mice, including the minute simulated heartbeats. They responded to these movements with visible twitches of the body, bursts of muscle activity, and associated increases in force exertion (Figs $7 \& 8$ ). In responses to prey movements, concave unilateral muscle activity was more pronounced than the occasional bilateral activity (Fig. 8). Snake responses to the simulated prey movements qualitatively seemed to be smallest for heartbeats, moderate for ventilatory movements, and largest for muscular, limb and whole body twitches. The muscular and force responses to brief struggling movements in prey were usually transient; however, repeated prey movements elicited larger, longer, and often stepwise responses (Figs $7 \& 8$ ).

The timing and magnitude of pressure varied considerably within and among constriction events. The constriction forces produced pressures of 9.5-19.1 kPa (71-143 $\mathrm{mm} \mathrm{Hg}$ ) in the body cavities of live mice and 6.1-30.9 kPa (46-232 mm Hg) in dead mice (Table 3). ANOVA results indicated that the peak pressures were not significantly different between living and dead prey (Table 3). The high variability in peak pressures within

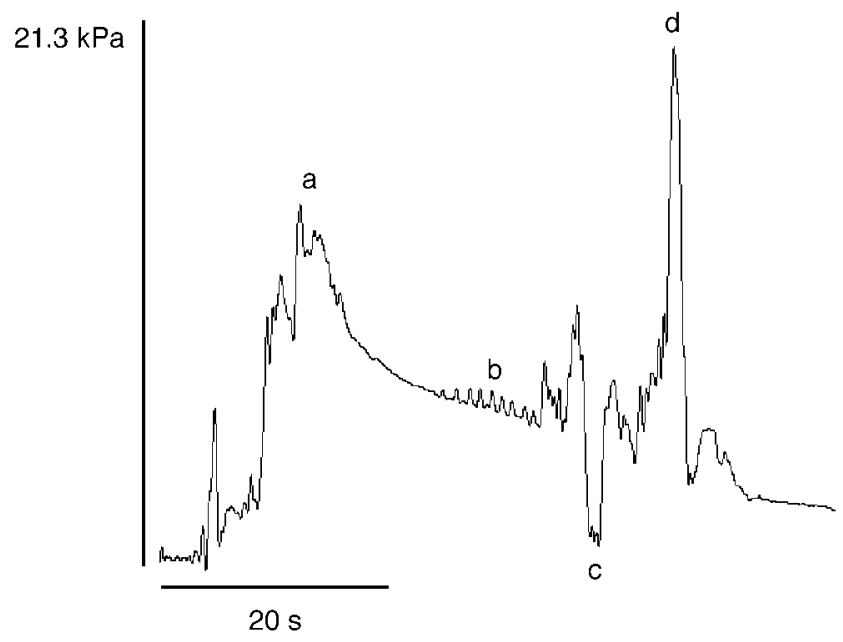

Fig. 7. Pressure responses to simulated limb and body movements (a) and ventilatory movements (b) during constriction of a dead mouse by Pituophis melanoleucus. Coil was loosened at point c; at peak $\mathrm{d}$, the snake pulled the mouse out of the coil to start swallowing it.

constriction events, among constriction events by a single individual, and among individuals indicated that force exertion is not uniformly or continuously maximal.

\section{Release of constriction}

During vigorous constriction and subsequent release of constriction posture, both gopher snakes and the king snake often seemed to pull on the prey with their jaws while the prey was still held in the loops or coil. These movements seemed to straighten and slightly stretch the prey.

Once the prey was killed, the snakes loosened the loops or coil, often in a stepwise pattern (Fig. 9). The snakes often began swallowing the prey while it was still surrounded by the loosened loops or coil. Some snakes occasionally began swallowing at the middle or posterior end of the prey animal's body, but these attempts were always abandoned, and all the snakes eventually swallowed the prey head-first.

\section{DISCUSSION}

\section{Muscular anatomy}

The epaxial musculature of the gopher snakes in this sample was similar to the patterns described for other populations of the same species, including Pituophis melanoleucus sayi (Mosauer, 1935; Jayne, 1982), P. m. annectens (Pregill, 1977), P. m. deserticola, P. m. lodingi, P. m. mugitus, and P. m. melanoleucus (Jayne, 1982). Pituophis m. affinis has SP muscle lengths that differ up to one vertebra (shorter or longer) and SP-SSP anterior 
(a)

LLD, V25

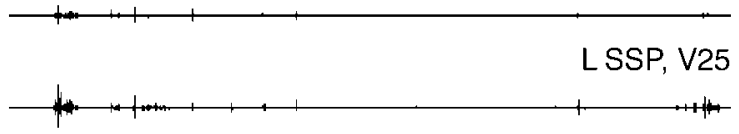

R SSP, V25
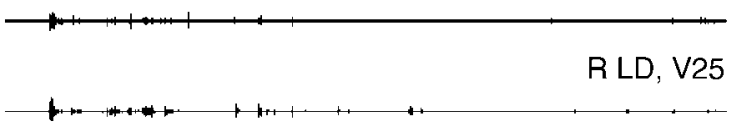

$11 \mathrm{kPa}$

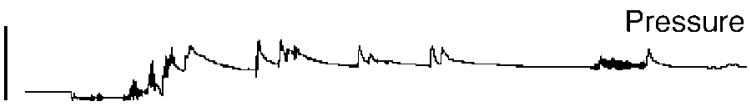

L LD, V75

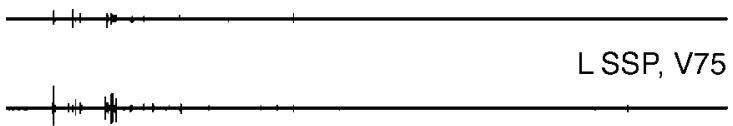

R SSP, V75

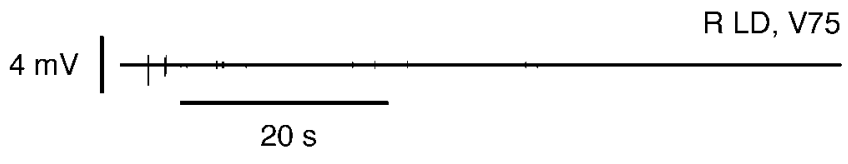

(b)

LSSP, V50

R SSP, V50

LSSP, V75
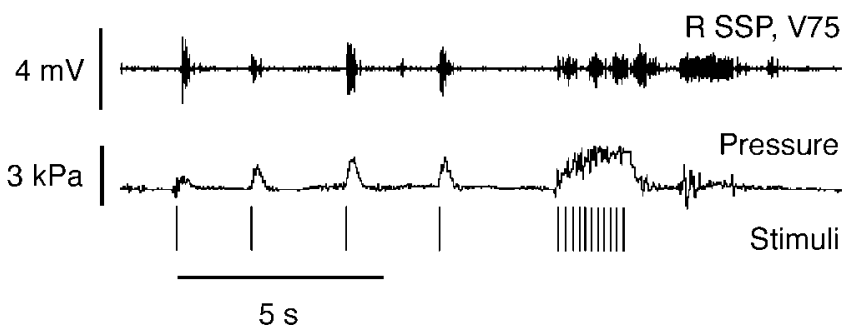

Fig. 8. Snake epaxial muscle activity and pressure responses to transient and repeated prey movements during constriction. (a) Real prey movements during a left lateral coil in Pituophis melanoleucus no. 13 . The electrodes at vertebra 25 were slightly anterior to the mouse, but the electrodes and muscles at vertebra 75 were in direct contact with the mouse. (b) Transient and repeated simulated prey movements (indicated by vertical bars) during a right lateral coil by Lampropeltis getula. Both electrode sites, at vertebrae 50 and 75 , were in direct contact with the mouse. Abbreviations as in Figs $1 \& 2$.

tendon lengths that are one to three vertebra shorter than in the other subspecies (Jayne, 1982). In addition, the diffuse tendon observed between the SSP and LD of $P$. $m$. affinis is slightly more diffuse than that reported by Mosauer (1935) for P. m. sayi. Thus, the SSP-LD tendon morphology of my sample is intermediate

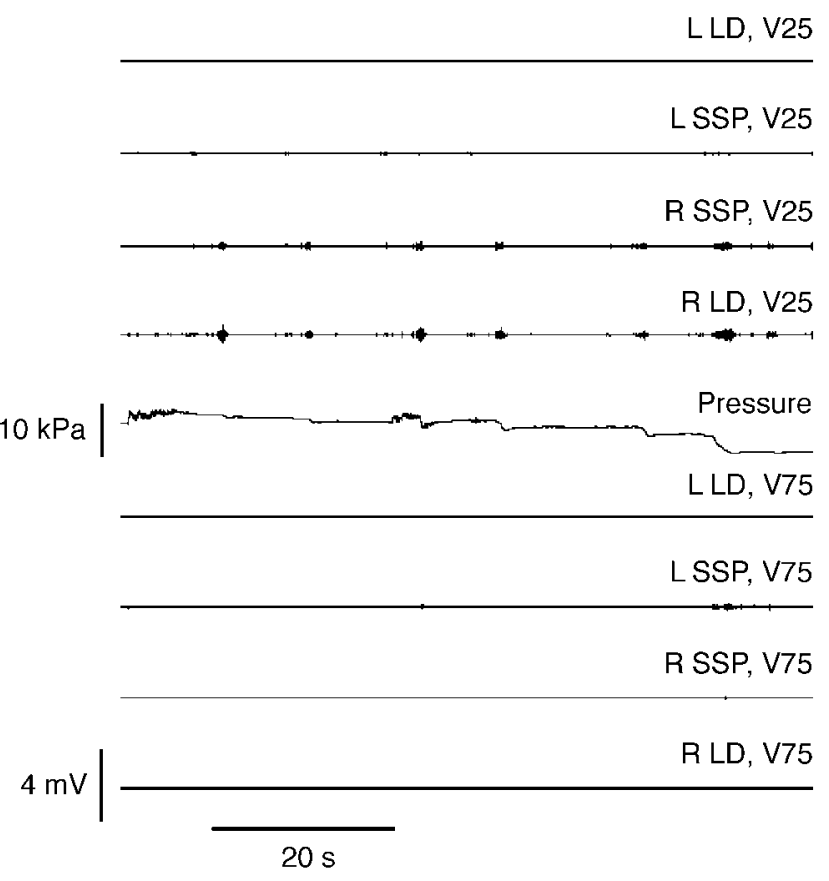

Fig. 9. Stepwise loosening of a left lateral constriction coil in Pituophis melanoleucus no. 13. The electrodes at vertebra 25 were slightly anterior to the mouse, but the electrodes and muscles at vertebra 75 were in direct contact with the mouse. Abbreviations as in Figs 1 \& 2 .

between Mosauer's (1935) type A morphology (SSP-LD tendon continuous through the intermuscular septum) of $P$. m. sayi and the type B morphology (LD tendon forms an aponeurosis in the intermuscular septum, and the SSP arises separately from the septum) that he reported for $L$. getula. These differences are not surprising given the variable external morphology among the widespread populations, and are probably mechanically insignificant. Dissection of larger samples of these two widespread and variable species will probably reveal continuous variation in muscle-tendon morphology.

\section{Potential factors that influence prey handling behavior}

Individuals of $P$. melanoleucus have highly versatile prey handling tactics. The different responses of the gopher snakes to living and freshly killed prey (which were maintained near live body temperatures) indicate that cues other than body temperature and movement influence the attack and handling strategies employed by the snakes. Comparable results from other studies indicate that many snakes assess prey movements and select handling tactics before contacting prey (Burghardt, 1966; McDonald, 1973; Herzog \& Burghardt, 1974; Drummond, 1979; de Queiroz, 1984). For example, prey handling tactics of racers Coluber constrictor differ for live and dead prey (Herzog \& Burghardt, 1974). Similarly, bull snakes $P$. m. sayi assess prey movements 
before striking and constrict active prey (adult mice) more often than inactive prey (neonate rats) of the same or even larger size (de Queiroz, 1984).

In many snakes, chemosensory cues also have strong effects on feeding behaviour (Herzog \& Burghardt, 1974; Ford \& Burghardt, 1993). Therefore, differences in chemosensory cues may influence the propensity of gopher snakes to constrict living and dead prey. In addition, the simulated movements of dead prey in this study may not have adequately represented the movements of live prey that elicit constriction.

My results do not support any specific inferences about the effects of particular prey cues on snake constriction behaviours, because multiple prey cues, which were not controlled in my experiments, may confound such inferences (Ford \& Burghardt, 1993). Nevertheless, the snakes seem to choose particular handling behaviours based on complex cues involving prey size, activity level and strength during struggling. The different cues produced by the prey, and the diverse handling behaviours employed by snakes in response to them, add a level of complexity to the optimal foraging model developed by Emerson, Greene \& Charnov (1994) based on predatory handling time and the size relationships between predators and prey.

I attempted to elicit maximal and prolonged constriction effort by simulating movements in dead mice and exaggerating movements in live mice. However, the highly variable constriction durations and forces indicated that the snakes did not respond uniformly or maximally. Rather than constrict with continuous maximal force, the snakes recruited epaxial muscle activity and exerted force only intermittently in response to movements of the prey. Although the small sample of simulated prey movements precluded statistical analysis of the snake responses to different prey movements, the snakes seemed to respond least strongly to the smallest prey movements (simulated heartbeats) and most strongly to the largest prey movements (real or simulated twitches of the legs or body). These results support the hypothesis that force is exerted only intermittently during constriction. Snakes seem to match constriction force, and therefore its energetic cost, to the need for subduing a particular prey animal.

\section{Coil formation and constriction postures}

Relative prey size affects the coil application behaviours of snakes. For example, in gopher snakes (this study) and pythons (Frazzetta, 1966) feeding on relatively small prey, loops are applied as the prey is retracted after the strike. However, with relatively large prey, gopher snakes apply loops by rolling forward over the prey, which is not retracted (Greenwald, 1978; this study). The latter method of coil formation conserves momentum and speeds the restraint of the prey, and therefore reduces the time and presumably also the energy required to subdue the prey. To retract the head plus the prey, a snake would have to reverse direction after the strike and accelerate the mass of the head plus the prey during retraction; this change of momentum would take considerable time and could allow the prey to attack or escape.

The variety of constriction postures observed in gopher snakes is consistent with the prey handling tactics reported in previous studies of gopher and bull snakes. Fully encircling loops, irregular loops and pinioning are commonly used by gopher snakes to constrict rodents (Hisaw \& Gloyd, 1926; Willard, 1977; Greenwald, 1978; de Queiroz, 1984).

In addition to its use by gopher and bull snakes, pinioning with looped or non-looped parts of the body is used by several other snakes, including Aspidites ramsayi (Shine, 1991), Drymarchon corais (Loop \& Bailey, 1972), several species of Elaphe (König, 1985; Mori, 1991; Schulz, 1996) and even the sea snake Fordonia leucobalia (Shine, 1991). Some limbless lizards also use a form of pinioning in which the prey is pressed down against the substratum (Gans, 1961). The use of pinioning appears to be convergent in these diverse taxa, although the evolution of this behaviour remains unstudied. All of the snakes that use pinions to restrain prey feed frequently in confined spaces such as animal burrows; in such spaces, pinioning allows a snake to restrain and kill a prey animal without having to form loops or a coil. In wild snakes, constriction postures probably vary even more than indicated in these studies, depending on the prey type, prey behaviour, and environmental circumstances.

\section{Sustained constriction}

\section{Kinematics}

Constriction involves vertebral curvatures and bending angles comparable to those of lateral undulation on average, but with larger peak values. The maximum vertebral bending angles in a constriction loop (up to $33^{\circ}$ per joint) exceed the maximum bending capacities of $25^{\circ}$ reported by Mosauer $(1932 a, b)$ and $12^{\circ}$ reported by Gasc $(1974,1976)$ and Jayne (1988a), but are within the limit of $44^{\circ}$ reported by Cundall (1995). However, these reports of bending capacities were measured on different parts of the trunk. Morphological variation along the vertebral column is known in many snakes (Johnson, 1955; Hoffstetter \& Gasc, 1969; Gasc, 1974, 1976; Rage \& Albino, 1989; Moon, 1999), and this variation may contribute to the highly variable maximal bending capacities reported for snakes.

\section{Muscle activity and force exertion}

The highly variable patterns of epaxial muscle activity obscure any simple correlations between epaxial muscle activity and the complex axial bending movements during constriction. Nevertheless, limited inferences can be drawn about the mechanical roles of the epaxial 
muscles in small-radius bending based on some of the kinematic, electromyographic and force exertion patterns observed.

(1) During constriction, the epaxial muscles fire with the same range of twitch rather than tonic spike frequencies as in locomotion. I was unable to detect lowfrequency activity characteristic of tonic fibre activity. Tonic fibre activity cannot be ruled out completely, however, because of the extreme sensitivity of tonic EMG signals to animal or wire movement, and because entire constriction events were not sampled for potential tonic activity.

(2) If present, unilateral muscle activity, particularly in concave bends of the body, would indicate clearly that the muscles contribute to small-radius bending during constriction. Although the patterns exhibited by gopher snakes and the king snake are not this clear, some patterns support the hypothesis that the epaxial muscles do contribute to small-radius axial bending: periods of unilateral epaxial muscle activity in regions of the trunk that contact the prey, coupled with increases in force exertion, indicate that the muscles contribute to smallradius bending during constriction. However, the precise mechanical roles of epaxial muscles in small-radius bends remain obscured, in part, by the following two possibilities.

(3) Muscle activity in part of the trunk in contact with the prey indicates that only part of a loop or coil may exert forces against the prey. The apparent decoupling of epaxial muscle activity and pressure in some constriction events probably resulted from the electrode-bearing muscles being in a part of the trunk that did not exert force against the prey.

(4) Alternatively, periods of small-radius bending with sustained force exertion, but without epaxial muscle activity, suggest that these muscles are not the only ones contributing to constriction postures and forces. Several of the small, deep hypaxial muscles probably contribute to sustained small-radius bends during constriction. For example, activity of the hypaxial $\mathrm{M}$. levator costae may move the ribs and body wall, which seem to be involved in tightening of fully formed coils. The combined crosssectional area of the hypaxial muscles may produce forces large enough to kill prey by constriction. Additional recordings of the numerous hypaxial muscles are clearly needed to develop a more thorough understanding of the design and mechanics of snake musculature.

Beyond these limited functional inferences, the roles of the epaxial muscles in small-radius axial bending during constriction remain unclear. However, epaxial muscle activity patterns in other behaviours allows some speculation about the roles of these muscles in constriction. Constriction involves several distinct movements: lifting of the head and neck, especially during striking and coil formation; occasional twisting in the loops; lateral bending; and apparent stretching of the prey, presumably by pulling apart of the loops or coil. Unilateral activity of the epaxial muscles, as well as at least one hypaxial muscle, contributes to lateral bending during snake locomotion (Jayne, 1988a,b; Gasc et al., 1989; Moon \& Gans, 1998). The oblique insertion angles of several vertebral muscles, including the $\mathrm{Mm}$. spinalis-semispinalis, multifidis and others, are mechanically suited to producing the twisting movements that are used during locomotion, feeding and defence by several snakes (Moon, 1999). As noted earlier, unilateral epaxial muscle activity is expected and seems to contribute to some constriction movements. Bilateral activity of the epaxial muscles is associated with lifting of the trunk during some kinds of locomotion (Jayne, 1988b) and during feeding (Moon, 1998). Similarly, bilateral muscle activity may contribute to the stretching movements of constriction, in which adjacent loops seem to be pulled slightly apart from one another by a complex form of vertebral dorsiflexion. These hypotheses may explain the apparent discrepancy between bilateral muscle activity and largely unilateral bending movements during constriction. However, they are currently only speculative and remain to be tested, which will require recording the activities of many of the small hypaxial muscles during different kinds of snake movements.

Muscle fibre types in colubrid snakes are typical of reptiles in general (Guthe, 1981). Although tonic fibres are present, special contractile properties such as a catch mechanism similar to that of bivalve molluscs have not been reported in reptiles. Furthermore, constriction pressure increases during muscular activity, and generally decreases during muscular inactivity; this was well illustrated whenever the electrode-bearing muscles were in loops that directly contacted the prey. As discussed above, constriction events in which pressure was sustained in the apparent absence of muscle activity probably reflect the electrode-bearing muscles not being in loops against the prey, although sustained tonic muscle activity cannot be ruled out. These results provide no evidence of any kind of catch mechanism in the epaxial muscles during constriction in snakes.

\section{Mechanical constraints}

The elongate epaxial muscles and tendons of colubrid snakes are hypothesized to bend long arcs of the trunk (Mosauer, 1932a,b; Gans, 1962; Ruben, 1977). The structure and use of the epaxial muscles support this hypothesis (Mosauer, 1935; Gasc, 1974, 1981; Jayne, 1988a; Moon \& Gans, 1998). However, Ruben (1977) argued that the elongate epaxial muscles and tendons of slender, fast snakes are incapable of shortening enough to produce small-radius bends, and thus impose a mechanical constraint against constriction.

Two previous lines of evidence have refuted the mechanical constraint hypothesis. Jayne (1982) reported that constrictors generally do not differ from nonconstrictors in the lengths of their epaxial muscles and tendons, which suggests that the elongate anatomy of the epaxial muscles is largely irrelevant to the capacity for constriction. Later, Shine \& Schwaner (1985) noted 
that many Australian elapid snakes are both fast locomotors and strong constrictors, which indicates that a trade-off is not present in the capacity for locomotor speed and constriction of prey.

In gopher snakes and the king snake, which are capable of moderate speed and vigorous constriction, the elongate epaxial muscles seem to contribute to small-radius axial bending, and clearly do not constrain the snakes from such bending. Therefore, even the highly variable activity of the epaxial muscles during constriction refutes Ruben's (1977) hypothesis of a mechanical constraint imposed by the elongate form of the muscles and their tendons. Instead, the loss of constriction in many snake lineages may have been the result of some anatomical, mechanical or physiological features other than the elongate form of the epaxial muscles. One hypothesis for a potential mechanical constraint is that in very slender snakes the small diameter of the body, and hence the small crosssectional area of the musculature, limits the force that can be produced during bending and coiling (Moon \& Candy, 1997).

\section{Comparative patterns and mechanisms}

The prey handling times, constriction movements and motor patterns of the single king snake were qualitatively similar to those of the gopher snakes, and were well within the range of variation exhibited by gopher snakes. These similarities suggest that these species employ similar mechanisms of bending and motor control when handling and constricting similar prey. However, because the sample of only one king snake precluded a more detailed examination of interspecific differences, these generalizations must remain tentative until more specimens can be tested. Further generalizations are not yet warranted, based on the single specimen and prey type tested.

\section{Effects of stretching on prey}

Gopher snakes (this study) and king snakes (this study; Klauber, 1972) often seem to stretch prey with the constricting loops. Many other snakes probably also stretch prey somewhat during constriction. Bilateral activity of the epaxial muscles during constriction may contribute to extension of the loops or coil, which would stretch the prey contained therein. Mechanical stretching is known to cause morphological and functional changes in peripheral nerves, although the strains required to do so are not well known (Kwan et al., 1992). For example, alteration of conduction properties can result from even a small stretch of $6 \%$ beyond the in situ length of the nerve (Kwan et al., 1992), and strains of $11 \%$ can compound these effects by reducing blood flow to the nerve by as much as $50 \%$ (Tanoue et al., 1996). Although muscular activity in struggling prey may prevent muscle, nerve and joint damage, excessive stretching during eccentric muscle activity may compound strain injuries when they occur (Garrett, 1990). The strains and muscular struggling activity in snake prey remain unstudied, but these data suggest that the physiological and mechanical effects of stretching during constriction aid in fatiguing or even damaging the prey.

\section{Effects of constriction pressure on prey}

The pattern of intermittent force exertion during sustained constriction posture supports the hypothesis that gopher, king and, presumably, other snakes seem to sustain muscle activity and force exertion only for as long as necessary to incapacitate their prey. This prey handling tactic potentially reduces the energetic cost of constriction without substantially reducing the ability of the snakes to reapply pressure quickly in response to movements of the prey. Similarly, stepwise release of constriction posture allows the snake to reapply pressures quickly if necessary.

The speed with which constriction usually kills small mammal prey led McLees (1928) and Hardy (1994) to hypothesize that constriction kills prey by inducing immediate circulatory arrest, rather than by suffocation. For example, simulated constriction kills wild woodrats (Neotoma albigula) in $79 \pm 14 \mathrm{~s}$ (Hardy, 1994) whereas asphyxiation alone takes three times as long (244 $\pm 22 \mathrm{~s})$ to kill lab rats of similar size (Hendrickx et al., 1984). I have been unable to find reports of asphyxiation time for mice, but simulated constriction kills domestic mice in as little as $42 \pm 5 \mathrm{~s}$ (Hardy, 1994), and brown tree snakes Boiga irregularis kill mice by constriction, without envenomation, in $50 \pm 19$ s (Rochelle \& Kardong, 1993). Both McLees (1928) and Hardy (1994) noted that suffocation would occur in conjunction with circulatory arrest, but the gradual hypoxia that develops from suffocation alone is probably not the proximate cause of death.

The durations of constriction recorded in this study were probably affected by manipulation of prey movements, and therefore may not be used to confirm the observations of McLees (1928) and Hardy (1994) that constriction kills rodents faster than suffocation. However, the pressures recorded in mice during constriction may be compared to the blood pressures of mice, and thus allow a test of the circulatory arrest hypothesis.

Domestic mice Mus musculus have systolic blood pressures of $13.1-16.7 \mathrm{kPa}(98-125 \mathrm{~mm} \mathrm{Hg}$; Turney \& Lockwood, 1986) and wild individuals of five species of field mice Peromyscus sp. have similar systolic blood pressures of $10.0-15.1 \mathrm{kPa}(75-113 \mathrm{~mm} \mathrm{Hg}$; Turney \& Lockwood, 1986). Therefore, the peak pressures of $6.1-30.9 \mathrm{kPa}(46-232 \mathrm{~mm} \mathrm{Hg}$; mean $=14.0 \mathrm{kPa}$ or 105 $\mathrm{mm} \mathrm{Hg}$ ) recorded in the body cavities of mice being constricted by gopher snakes and the king snake ranged from about half to twice the mouse's systolic blood pressure. As the peripheral and venous blood pressures 
are roughly 10 times lower than the systolic pressures, constriction pressures are very much larger than the peripheral and venous blood pressures of mice.

Forces exerted on the body of a prey animal during constriction are transmitted to the pericardial space, where they may interfere with circulation and heart function (Hardy, 1994; Kaplan et al., 1995). Experiments on dogs have shown that pleural pressures as low as $4 \mathrm{kPa}(30 \mathrm{~mm} \mathrm{Hg})$ above ambient pressure lead to rapid deterioration of cardiac circulation and function; pressures above $8 \mathrm{kPa}(60 \mathrm{~mm} \mathrm{Hg})$ induce myocardial ischaemia (Fessler et al., 1990). In the pericardial space, much lower pressures (e.g. as low as $0.4 \mathrm{kPa}$, or $3 \mathrm{~mm}$ $\mathrm{Hg}$, above left ventricular diastolic pressure; Schwartz et al., 1993) around the heart and circulatory vessels are sufficient to compress the atria, vena cavae and pulmonary veins (Fowler \& Gabel, 1985, 1987), reduce atrial filling pressures (Louie et al., 1995), and cause ventricular diastolic collapse (Beppu et al., 1990; Vaska et al., 1992). These effects, from relatively low external pressures, can rapidly lead to circulatory and cardiac arrest.

Therefore, the large forces exerted on mice by the snakes provide strong, although indirect, support for the hypothesis of McLees (1928) and Hardy (1994) that constriction induces rapid circulatory and cardiac arrest in mammalian prey. In addition to killing prey faster than suffocation alone, circulatory and cardiac arrest would minimize the energetic cost of constriction and potential injury by the struggling prey. Note, however, that my results indicate that although gopher snakes and the king snake have the capacity to constrict mice with enough force to induce circulatory arrest, they may not always constrict with maximal force. Direct measurements of blood pressure and flow in prey being constricted may resolve whether constriction actually does induce circulatory and cardiac arrest in their prey.

\section{Acknowledgments}

This research was approved by the University Committee on the Use and Care of Animals at The University of Michigan. Snakes were collected with a permit from the Arizona Fish and Wildlife Department and help from George Ferguson, George Good, Rob Raguso, Cecil Schwalbe and Tom Taylor; Russell Burke, Dan Erickson and Nate Kley provided some snakes for the supplementary observations. Nate Kley generously shared his X-ray video data on coil tightening in pine snakes. Carl Gans, Harry Greene, David Hardy Sr, Nate Kley and Katherine Wadsworth provided valuable advice on various stages of this work. Mark Brahce, the Department of Biology, and the Media Services of The University of Michigan all provided important equipment. This research was funded by the Department of Biology and Rackham Graduate School of the University of Michigan.
Support for presentation of this work at several conferences was provided by the Department of Biology and Rackham Graduate School of the University of Michigan, and by the Herpetologists League and the Society for the study of amphibians and reptiles.

\section{REFERENCES}

Alexander, A. A. \& Gans, C. (1966). The pattern of dermalvertebral correlation in snakes and amphisbaenians. Zool. Meded. 41: 171-190.

Bennett, R. A. (1996). Anesthesia. In Reptile medicine and surgery: 241-247. Mader, D. R. (Ed.). Philadelphia, PA: Saunders.

Beppu, S., Ikegami, K., Izumi, S., Nakajima, S., Nakatani, S., Miyatake, K. \& Nimura, Y. (1990). Venous return and collapse of the right heart in cardiac tamponade. J. Cardiol. 20: 945-956.

Burghardt, G. M. (1966). Stimulus control of the prey attack response in naive garter snakes. Psychon. Sci. 4: 37-38.

Carrier, D. (1989). Ventilatory action of the hypaxial muscles of the lizard Iguana iguana: a function of slow muscle. J. exp. Biol. 143: 435-457.

Cundall, D. (1987). Functional morphology. In Snakes: ecology and evolutionary biology: 106-140. Seigel, R. A., Collins, J. T. \& Novak, S. S. (Eds). New York: McGraw-Hill.

Cundall, D. (1995). Feeding behaviour in Cylindrophis and its bearing on the evolution of alethinophidian snakes. J. Zool. (Lond.) 237: 353-376.

Cundall, D. \& Greene, H. W. (1982). Evolution of the feeding apparatus in alethinophidian snakes. Am. Zool. 22: 924.

de Queiroz, A. (1984). Effects of prey type on the prey-handling behavior of the bullsnake, Pituophis melanoleucus. J. Herpetol. 18: $333-336$.

Drummond, H. M. (1979). Stimulus control of amphibious predation in the northern water snake (Nerodia s. sipedon). Z. Tierpsychol. 50: 18-44.

Emerson, S. B., Greene, H. W. \& Charnov, E. L. (1994). Allometric aspects of predator-prey interactions. In Ecological morphology: integrative organismal biology: 123-139. Wainwright, P. C. \& Reilly, S. M. (Eds). Chicago, IL: University of Chicago Press.

Fessler, H. E., Brower, R. G., Wise, R. \& Permutt, S. (1990). Positive pleural pressure decreases coronary perfusion. Am. J. Physiol. 258: H814-H820.

Ford, N. B. \& Burghardt, G. M. (1993). Perceptual mechanisms and the behavioral ecology of snakes. In Snakes: ecology and behavior: 117-164. Seigel, R. A. \& Collins, J. T. (Eds). New York: McGraw-Hill.

Fowler, N. O. \& Gabel, M. (1985). The hemodynamic effects of cardiac tamponade: mainly the result of atrial, not ventricular, compression. Circulation 71: 154-157.

Fowler, N. O. \& Gabel, M. (1987). Regional cardiac tamponade: a hemodynamic study. J. Am. Coll. Cardiol. 10: 164-169.

Frazzetta, T. H. (1966). Studies on the morphology and function of the skull in the Boidae (Serpentes). Part II. Morphology and function of the jaw apparatus in Python sebae and Python molurus. J. Morphol. 118: 217-296.

Gans, C. (1961). The feeding mechanism of snakes and its possible evolution. Am. Zool. 1: 217-227.

Gans, C. (1962). Terrestrial locomotion without limbs. Am. Zool. 2: $167-182$.

Garrett, W. J. (1990). Muscle strain injuries: clinical and basic aspects. Med. Sci. Sports Exerc. 22: 436-443.

Gasc, J.-P. (1974). L'interprétation fonctionnelle de l'appareil musculo-squelettique de l'axe vertébral chez les Serpents (Reptilia). Mém. Mus. Natl. Hist. Nat. Ser. A Zool. 83: 1-182. 
Gasc, J.-P. (1976). Snake vertebrae - a mechanism or merely a taxonomist's toy? In Morphology and biology of reptiles. Bellairs, A. d'A. \& Cox, C. B. (Eds). Linn. Soc. Symp. Ser. 3: 177-190.

Gasc, J.-P. (1981). Axial musculature. In Biology of the Reptilia 11: 355-435. Gans, C. \& Parsons, T. S. (Eds). New York: Academic Press.

Gasc, J.-P., Cattaert, D., Chasserat, C. \& Clarac, F. (1989). Propulsive action of a snake pushing against a single site: its combined analysis. J. Morphol. 201: 315-329.

Greene, H. W. (1983). Dietary correlates of the origin and radiation of snakes. Am. Zool. 23: 431-441.

Greene, H. W. (1994). Homology and behavioral repertoires. In Homology: the hierarchical basis of comparative biology: 369-391. Hall, B. K. (Ed.). San Diego, CA: Academic Press.

Greene, H. W. \& Burghardt, G. M. (1978). Behavior and phylogeny: constriction in ancient and modern snakes. Science 200: 74-77.

Greenwald, O. E. (1974). Thermal dependence of striking and prey capture by gopher snakes. Copeia 1974: 141-148.

Greenwald, O. E. (1978). Kinematics and time relations of prey capture by gopher snakes. Copeia 1978: 263-268.

Guthe, K. F. (1981). Reptilian muscle: fine structure and physiological parameters. In Biology of the Reptilia 11: 265-354. Gans, C. \& Parsons, T. S. (Eds). New York: Academic Press.

Hardy, D. L. (1994). A re-evaluation of suffocation as the cause of death during constriction by snakes. Herpetol. Rev. 229: 45-47.

Hendrickx, H. H., Rao, G. R., Safar, P. \& Gisvold, S. E. (1984). Asphyxia, cardiac arrest and resuscitation in rats. I. Short term recovery. Resuscitation 12: 97-116.

Herzog, H. A. \& Burghardt, G. M. (1974). Prey movement and predatory behavior of juvenile western yellow-bellied racers, Coluber constrictor mormon. Herpetologica 30: 285-289.

Hisaw, F. L. \& Gloyd, H. K. (1926). The bull snake as a natural enemy of injurious rodents. J. Mammal. 7: 200-205.

Hoffstetter, R. \& Gasc, J.-P. (1969). Vertebrae and ribs of modern reptiles. In Biology of the Reptilia 1: 201-310. Gans, C., Parsons, T. S. \& Bellairs, A. d'A. (Eds). New York: Academic Press.

Jayne, B. C. (1982). Comparative morphology of the semispinalisspinalis muscle of snakes and correlations with locomotion and constriction. J. Morphol. 172: 83-96.

Jayne, B. C. (1988a). Muscular mechanisms of snake locomotion: an electromyographic study of lateral undulation of the Florida banded water snake (Nerodia fasciata) and the yellow rat snake (Elaphe obsoleta). J. Morphol. 197: 159-181.

Jayne, B. C. (1988b). Muscular mechanisms of snake locomotion: an electromyographic study of sidewinding and concertina modes of Crotalus cerastes, Nerodia fasciata, and Elaphe obsoleta. J. exp. Biol. 140: 1-33.

Jayne, B. C., Lauder, G. V., Reilly, S. M. \& Wainwright, P. C. (1990). The effect of sampling rate on the analysis of digital electromyograms from vertebrate muscle. J. exp. Biol. 154: $557-565$.

Johnson, R. G. (1955). The adaptive and phylogenetic significance of vertebral form in snakes. Evolution 9: 367-388.

Kaplan, L. M., Epstein, S. K., Schwartz, S. L., Cao, Q. L. \& Pandian, N. G. (1995). Clinical, echocardiographic, and hemodynamic evidence of cardiac tamponade caused by large pleural effusions. Am. J. Respir. Crit. Care Med. 151: 904-908.

Klauber, L. M. (1972). Rattlesnakes: their habits, life histories, and influence on mankind. Berkeley, CA: University of California Press.

König, D. (1985). Langjährige beobachtungen an der Äskulapnatter Elaphe longissima (Laruenti, 1768). Salamandra 21: 17-39.

Kwan, M., Wall, E., Massie, J. \& Garfin, S. (1992). Strain, stress and stretch of peripheral nerve. Rabbit experiments in vitro and in vivo. Acta Orthop. Scand. 63: 267-272.
Loeb, G. E. \& Gans, C. (1986). Electromyography for experimentalists. Chicago, IL: University of Chicago Press.

Loop, M. S. \& Bailey, L. G. (1972). The effect of relative prey size on the ingestion behavior of rodent-eating snakes. Psychon. Sci. 28: 167-169.

Louie, E. K., Hariman, R. J., Wang, Y., Hwang, M. H., Loeb, H. S. \& Scanlon, P. J. (1995). Effect of acute pericardial tamponade on the relative contributions of systolic and diastolic pulmonary venous return: a transesophageal pulsed Doppler study. Am. Heart J. 129: 124-131.

McDonald, L. (1973). Attack latency of Constrictor constrictor as a function of prey activity. Herpetologica 29: 45-48.

McLees, F. (1928). Killing by constriction. Bull. Antivenin Inst. America 1: 105.

Moon, B. R. (1996). Sampling rates, aliasing, and the analysis of electrophysiological signals. In Proceedings of the Fifteenth Southern Biomedical Engineering Conference: 401-404. Bajpai, P. K. (Ed.). Piscataway, NJ: IEEE Service Center.

Moon, B. R. (1998). Structural and functional integration of the snake axial system. $\mathrm{PhD}$ thesis, University of Michigan.

Moon, B. R. (1999). Testing an inference of function from structure: Snake vertebrae do the twist. J. Morphol. 241: 217-225.

Moon, B. R. \& Candy, T. (1997). Muscular and coelomic crosssectional areas in three families of snakes. J. Herpetol. 31: $37-44$.

Moon, B. R. \& Gans, C. (1998). Kinematics, muscular activity, and propulsion in gopher snakes. J. exp. Biol. 201: 2669-2684.

Mori, A. (1991). Effects of prey size and type on prey-handling behavior in Elaphe quadrivirgata. J. Herpetol. 25: 160-166.

Mosauer, W. (1932a). On the locomotion of snakes. Science 76: 583-585.

Mosauer, W. (1932b). Über die Ortsbewegung der Schlangen: eine Kritik und Ergänzung der Arbeit Wiedemann's. Zool. Jahrb. (Zool.) 52: 191-215.

Mosauer, W. (1935). The myology of the trunk region of snakes and its significance for ophidian taxonomy and phylogeny. Univ. Calif. Publ. Biol. Sci. 1: 81-120.

Pregill, G. K. (1977). Axial myology of the racer Coluber constrictor with emphasis on the neck region. Trans. San Diego Soc. Nat. Hist. 18: 185-206.

Rage, J.-C. \& Albino, A. M. (1989). Dinilysia patagonica (Reptilia, Serpentes): matériel vertébral additionnel du Crétacé supérieur d'Argentine. Etude complémentaire des vertébres, variations intraspécifique et intracolumnaires. Neues Jahrb. Geol. Paläeontol. Monatshefte 1989: 433-447.

Rochelle, M. J. \& Kardong, K. V. (1993). Constriction versus envenomation in prey capture by the brown tree snake, Boiga irregularis (Squamata: Colubridae). Herpetologica 49: 301-304.

Ruben, J. A. (1977). Morphological correlates of predatory modes in the coachwhip (Masticophis flagellum) and rosy boa (Lichanura roseofusca). Herpetologica 33: 1-6.

Schulz, K.-D. (1996). A monograph of the colubrid snakes of the genus Elaphe Fitzinger. Czech Republic: Koeltz Scientific.

Schwartz, S. L., Pandian, N. G., Cao, Q. L., Hsu, T. L., Aronovitz, M. \& Diehl, J. (1993). Left ventricular diastolic collapse in regional left heart cardiac tamponade: an experimental echocardiographic and hemodynamic study. J. Am. Coll. Cardiol. 22: 907-913.

Shine, R. (1991). Australian snakes: a natural history. Ithaca, NY: Cornell University Press.

Shine, R. \& Schwaner, T. (1985). Prey constriction by venomous snakes: a review and new data on Australian species. Copeia 1985: 1067-1071.

Tanoue, M., Yamaga, M., Ide, J. \& Takagi, K. (1996). Acute stretching of peripheral nerves inhibits retrograde axonal transport. J. Hand Surg. 21: 358-363. 
Turney, T. H. \& Lockwood, J. A. (1986). Systolic blood pressure in Peromyscus species: considerations for the murine hypertension model. J. Zool. (Lond.) 209: 149-154.

Vaska, K., Wann, L. S., Sagar, K. \& Klopfenstein, H. S. (1992).
Pleural effusion as a cause of right ventricular diastolic collapse. Circulation 86: 609-617.

Willard, D. E. (1977). Constricting methods of snakes. Copeia 1977: $379-382$. 